\title{
LOCUS OF CONTROL AND CROSS-CULTURAL ADJUSTMENT OF EXPATRIATE MANAGERS
}

Stella Flytzani

Athens University of Economics and Business

Dept. of Marketing and Communications

Athens

stella_flytziani@yahoo.com
Peter Nijkamp

Free University

Dept. of Spatial Economics

Amsterdam

pnijkamp@feweb.vu.nl

\begin{abstract}
International labour mobility is becoming a key feature of a globalizing world. There is an increasing amount of literature on the success and failure conditions of migrant workers. A particular class of foreign workers is formed by so-called expatriates who are sent on a temporary basis (several years normally) by a parent company located in a given country to live and work in another country, notably as an employee in a subsidiary abroad.

This paper aims to investigate the performance of expatriate managers by explaining their cross-cultural adjustment potential from their personal management style features. These features are derived from the concept of locus of control in social learning theory, in which two types of responses to challenges are distinguished: internals (controlling events themselves) and externals (following outside forces). Based on a sample of 43 individuals, our study concludes that managers with an internal locus of control are more successful in coping with the difficulties inherent in adjusting to a foreign culture.
\end{abstract}




\section{Labour Mobility in an Age of Globalization}

Our age of globalization has meant an unprecedented cross-the-border dynamics. Regions, nations, industries and people are in a permanent state of flux in which geographical mobility plays a prominent role. This is clearly reflected in international migration, transport and communication. The business sector is not an exception to this trend and becomes increasingly globally oriented, with subsidiaries in many foreign countries (for instance, as a result of outsourcing) (cf. Dresser 1996). These subsidiaries tend to employ many domestic workers from the host country in which they are located, but management functions are often - at least partly - filled by personnel sent by the head office of the parent company concerned. Usually these employees receive a temporary assignment (often for two years or more). These employees are usually called expatriates. They plan to return to their home country, so that such managers may be regarded as temporary migrants. The normal length of their stay is however, sufficiently long to necessitate them to adjust to the local culture in their new host country. Creative managers will certainly make a serious effort to familiarize themselves with the prevailing habits, culture and traditions in their new temporary home country, and certainly in regard to their daily professional work (cf. Basu and Altinay 2002, Casson 1995, and Littunen 2000).

There is an abundance of literature on the integration, assimilation and segregation conditions of migrants (see e.g., Gorter et al. 1998). Migration in our modern age is closely connected with the international openness of the global space-economy, in which both households and business firms tend to extend their action radius beyond national borders.

The globalization of business life - instigated by fierce competition in a liberalized world economy with turbulent changes - has created a new type of doing business, leading to footholds of a parent company in many countries, a phenomenon that was stimulated by technological progress, recent ICT developments and a new industrial organization of work (cf. Gertler 2004). The onset of the globalization era has led to intensified interaction among business companies and their managers from different countries and cultures. It is nowadays commonly accepted that it is imperative for 
multinational companies to attract, select, train and retain employees who are able to work and stay effectively outside their own national borders (see, for instance, Adler and Bartholomew 1992, Black et al. 1992, Light and Gold 2000, Mendenhall and Oddou 1985, Stroh and Caligiuri 1998, Tung 1981, 1988, Tung and Miller 1990). This dynamic business environment has induced the phenomenon of expatriates, a phenomenon that is rapidly gaining importance in modern industrial organizations (see e.g., Laabs 1993, Stroh et al. 1994). It goes without saying that this new expatriates trend prompts various habitual and behavioural challenges in adjusting to a new cultural environment; expatriate executives have to perform usually in an unfamiliar work context and have to encounter and adopt a different way of life and management style than in their own country.

Over the past years several studies have been carried out to study the order of magnitude, the success conditions and the performance of expatriate managers (EXMs). We will offer here a concise overview of findings from a few selected studies. In a combined study by Windham International and the National Foreign Trade Council, Inc. (1994) - carried out mainly on US multinational corporations - the results are reported from a so-called Conference Board survey in two years, 1992 and 1994. In the first survey, held among 130 multinational organizations, it was found that at least half of these organizations had more than 50 high-level managers currently on global assignments. In the subsequent 1994 survey, held among 103 multinational organizations, it turned out that the number of their global assignments had increased - with respect to the previous survey period - with approx. $30 \%$, while $71 \%$ of the respondents were of the opinion that this pace of rapid growth would continue in the future.

In some earlier studies (see Baker and Ivancevich 1971; Tung 1981) it was found that approx. 20 to $40 \%$ of the EXMs were not successful in making a transition to a foreign country and, consequently, returned earlier. These figures would even be higher if one would include also 'brownouts' (see Lanier 1979) and EXMs who may not return earlier, but perform at a sub-optimal level due to insufficient adjustment to their new work roles. Other earlier studies (see e.g. Adams and Kobayashi 1969, Copeland and Griggs 1985, Seward 1975) estimated that 50 to 80\% of American EXMs are considered 
ineffective by their firms. Also British and German companies have been criticized for inadequate preparation of their staff sent abroad.

The costs of inadequate functioning of EXMs may be significant to their organizations. Harris (1979) has estimated that the costs involved with an early return of an EXM from an international assignment may amount to a range of \$ 50.000 to \$ 150.000 per person. Against this background, it is imperative for a large multi-national company to get a better understanding of the success and failure factors of EXMs and the type of skills needed to make a stay abroad successful. For example, training courses for executives on cross-cultural management practices might be a useful vehicle for a better understanding and adjustment. Of course, there are questions whether the key to success rests with smart foreign strategies, with organizational structures, with creative technological innovations or with human resource management. For example, Black et al. (1999) argue that people are the key, as they design and implement strategies, build and deploy organizational structures, and invent and use proper technologies. Many studies suggest indeed that the acquisition of a globalisation attitude by people is the key to the success of competitive international business. In the sequel of this study the latter proposition will be further investigated and tested. We will introduce two concepts from the theory on organization culture, viz. locus of control (LOC) and individual crosscultural adjustment (CCA). The next section will address CCA, while Section 3 will deal with LOC. In subsequent sections we will then describe our case study and present our empirical findings.

\section{Cultural Adjustment from the Perspective of Organizational Culture}

Culture is a broad concept and refers to customary and traditional ways of behaviour and attitude that are largely shared by the members of a community or organization. From this perspective, it is plausible that culture will have an impact on the appropriation of certain behavioural styles. This is also important from the viewpoint of the internationalisation of business life which by definition implies a confrontation with and exposure to diverse cultures. Culture specificity may have a great impact on successful organisational or managerial practices in different nations or regions. 
The interface culture-organization has been extensively addressed in the cultural classification system of Hofstede (1980, 1984, 1994). In this work he distinguishes four basic dimensions inherent in typifying and classifying cultures and behavioural or attitudinal styles related to cultures:

- $\quad$ power distance superiors - subordinates

- $\quad$ uncertainty - avoidance of risk

- $\quad$ individualism - collectivism in group behaviour

- $\quad$ masculinity - femininity in performance perception.

The original study by Hofstede (1980) was based on two survey questionnaires of employees in a large multinational corporation that operated in over 100 different countries. Using the above classification system the author was able to compose 8 distinct cultural groups of countries with a high degree of both internal homogeneity and external heterogeneity. He found clear and systematic differences in work-related attitudes among the different cultural groups and it seems plausible that these features would be responsible for differences in organizational processes and patterns of behaviour. In conclusion, Hofstede's theory is based on the assumption that cultural values in each group may induce different conceptions of what is appropriate behaviour in a given context, so that management practices and organizational processes are likely not the same everywhere.

Clearly, it may be argued that the sample has a limited validity (it was drawn from a single large company) (see Tyson and Jackson 1992), or that national boundaries are treated as synonymous to national cultures (while neglecting intra-national cultural variations), or that this study does not explain cultural differences (it takes these for granted) (see Furnham and Gunter 1993). Nevertheless, Hofstede's work may be seen as pioneering research that has prompted many other studies on the implications of cultural differences for management behaviour (see Triandis 1982), which have largely confirmed Hofstede's findings (see e.g. Laurent 1983, Ronen and Shenkar 1985).

In general, an internationally operating company with subsidiaries abroad will try to develop a human resource management that takes into account the above mentional cultural factors. EXMs are expensive (in terms of compensation, benefit transfers and 
other costs) and, in order to get the most out of such an investment, the mother company will therefore normally carefully recruit EXMs on the basis of their skills and expected potential in a foreign culture. Technical skills are not necessarily equal to the best CCA skills, while the second factor is often responsible for ineffective CCA by expatriates and their families. Thus, a successful completion of an international assignment of EXMs is often contingent on their individual CCA. It is therefore evident that finding suitable candidates for international assignments - with a high degree of personal flexibility and CCA potential - is a major challenge for most multinationals nowadays. Consequently, it is of utmost importance to have due insight into the effective cultural flexibility of EXMs, but this topic has not extensively or thoroughly been investigated. Some exceptions are Tung (1981, 1988), Black (1990), Torbiorn (1982) or Weissman and Furnham (1987). In general, CCA may be defined in operational terms as the degree of a persons' psychological comfort with various relevant aspects (attributes) of a new setting in a culturally different environment (see e.g, Black 1998, and Nicholson 1984). When this adjustment concerns relatively short-term visitors/workers in a new culture (e.g., a couple of years) - without the explicit aim of permanent settlement -, it is often referred to as sojourner adjustment (see Church 1982). CCA studies have already a long history and date back to Lysgaard's (1955) study on the adjustment of Norwegian students who had received a Fullbright scholarship. The theoretical basis for this research was later provided by the cultural shock theory (see studies by Oberg 1960, and later on by Torbiorn 1982). This theory rests essentially on the argument that people entering a new country and culture discover that certain behaviours which were common or acceptable in their home country are no longer appropriate or effective in the new host country. Against this background, Weissman and Furnham (1987) claim that cultural shock is a stress reaction where salient psychological and physical rewards are generally uncertain. Consequently, these factors that may reduce uncertainty on the appropriateness of behaviours will likely facilitate a better adjustment. In the course of history, several frameworks to identify these determining factors have been developed, such as the stage theory (see Oberg 1950) or the U-curve adjustment theory (see Lysgaard 1955), but the results of these analysis frameworks are not always conclusive or convincing. In more recent periods, many attempts have been undertaken to develop a more rigorous or 
cohesive model of CCA (see in particular, Black 1990, 1998, Black et al. 1999, and Black and Gregersen 1991), but it has become evident that not all expatriates experience the same cultural shock or exhibited similar patterns of adjustment, so that the attention of researchers shifted towards personal characteristics of expatriates that might distinguish successful from unsuccessful sojourners (see e.g., Stening 1979, Church 1982, Mendenhall and Oddou 1985, Ringer and Boss 2000). Is there a universally successful adjustment model, like the universal communicator as described by Gardner (1962)? So far, no statistical evidence has been found, and hence research has focused more on individual differences in the perception of stressors and stress situations (see e.g., Kelman and Bailyn 1962, or Spector et al. 2002).

There have been several attempts to design an operational measure. The most widely used measurement for this variable is based on the scale developed by Black (1998). This scale contains 11 items in the forms of statements on adjustment to work conditions, responsibilities, living in a foreign culture etc. Each actor is asked to rate each statement on a scale from 1 (not adjusted) to 7 (very well adjusted). Next, statistical mean scores are calculated for each actor which reveals their degree of adjustment to living and working in a country with a different culture.

It is increasingly recognized that personal dispositions may interact with situational factors in a reciprocal or transactional manner to influence the adjustment of the sojourner, for instance, ethnocentricity, openness to people, or sociability (see e.g., Black et al. 1999, Bono and Judge 2003, Caligiuri 2000, and Judge et al. 1998). From this perspective, the concept of LOC (see Rotter 1966) offers an interesting link between a

personality characteristic and organizational behaviour, as important factors such as motivation, effort, performance, satisfaction, job perception, compliance with authority or supervisory style can be taken into consideration. This concept will be further introduced in the next section.

\section{Locus of Control}

The LOC theory has been developed several decades back by Rotter (1966, 1975, 1990) who made a distinction between internal and external response mechanisms of an 
individual exposed to a new challenge. An internal control expectation refers to a behavioural response of an actor who acts out of his/her own strength on the basis of his/her own structural characteristics. An external control expectation means an attitude co-determined by the actions or decisions of other people or exogenous circumstances. Internal control behaviour presupposes the willingness to learn and to adjust, and is thus based on active striving, whereas external control behaviour frustrates learning and takes for granted a passive attitude to the external world (see also Levenson 1981, and Rotter et al. 1972). Internals and externals are thus two types of different species, where the general hypothesis is that for active challenges faced by actors (entrepreneurs, migrants), internals tend to be more successful than externals, since internals seek actively for the use of memorized information for problem solving based on belief in themselves. Consequently, internals do normally exhibit less conformity than externals. Furthermore, externals tend to be more anxious than internals (see Joe 1971, Archer 1979), while in terms of social desirability and achievement motivation a conclusive relationship with the LOC could not be found. A recent extensive overview of LOC and a quantitative assessment of LOC results by means of meta-analysis can be found in $\mathrm{Ng}$ et al. (2006).

As far as the LOC in an organizational context is concerned, it should be noted that the attempts of internals to control the work setting may be manifested in various ways. An internal will likely aim to control work flows, task accomplishment, operating procedures, work assignments, relationships with supervisors and subordinates, working conditions, goal setting, work scheduling and organizational policy. They are inclined to do so, as they perform better in learning and problem solving situations, inter alia by actively acquiring relevant information. Consequently, internal control attitude seems to be a good predictor of motivation and performance in uncertain conditions, in particular since internals are generally more responsive than externals (especially if appropriate performance-reward contingencies are presented).

Externals on the other hand, are more conforming and compliant than internals, as they tend to look at others and expect also subordinate behaviour based on assumed submissiveness to authoritarians. For example, Goodstadt and Hjelle (1973) found that externals tend to use a coercive leadership style when dealing with subordinates. It depends thus on the nature of a job whether an internal or external control style is 
successful. One may expect that in case of complex information processing and frequent complex learning, internals do perform better than externals. But for simple tasks of a routine nature this difference may vanish. If a given task is characterized by taking initiatives and independent actions, the internal may be very suitable, but when the task requires high compliance, an external attitude is more appropriate. In conclusion, internals are likely best suited for complex technical or skilled jobs, demanding professional tasks or creative managerial or supervisory jobs, whereas externals are likely to be best suited for factory line jobs, unskilled work, clerical jobs, and jobs of a routine nature (see also Judge et al. 1998, Marin et al. 2005, and Wong and Sproule 1984).

The most widely used tool for measuring the LOC is Rotter's (1961) internal external scale, which consists of 23 LOC items in a standard (forced) 0-1 pairwise choice format. The score is calculated by summing up the total of externally-oriented responses for each pair. Thus, the Rotter score ranges from 0 to 23, with low scores indicating a strong internality and high scores a high externality. According to this score, participants can be classified as either internal or external.

It is evident that the behaviour of EXMs may be characterized by complex work ramifications, non-standard expatriate assignments, confrontation with unusual organizational culture and multi-faceted cross-cultural adjustment issues. The LOC concept may then be instrumental in identifying the right people for the right task, given their personal characteristics (see Church 1982, Spector 1982), based on the assumption to be tested in empirical research - that internal EXMs have a higher performance on a cross-cultural adjustment scale than externals (see also Selmer 2002). Consequently, the hypothesis to be tested in our empirical field study is the following: internals will perform better than externals when required to adjust in a foreign culture. This hypothesis will now be tested on the basis of empirical research among EXMs in Great Britain.

\section{Case Study}

Our case study was addressed to EXMs in Great Britain. The field work is based on survey questionnaires mailed to or personally handed over to EXMs working in various multinational companies, who were either currently on an expatriate assignment 
or had been on one in the recent past in this country. These EXMs had no prior expatriate assignment in their record. The questionnaires contained questions on the personal situation of the respondent (like age, profession, gender, marital status etc.). Furthermore, they contained all questions to calculate the above mentioned cross-cultural adjustment score as well as the LOC indicator. A total of 50 questionnaires was sent out, with a surprisingly high response rate of $86 \%$ (i.e., a total of 43 returned questionnaires). After carrying out the descriptive statistics for the data in order to calculate the relationship between the two categories of scores, an independent sample t-test as well as a MannWithney test were carried out (see later). Our experiment is based on a repeated-measures design. The independent variable is the LOC score, while the dependent variable is the CCA score based on Black $(1990,1998)$.

In the present section we will investigate - on the basis of our limited case study the validity of our hypothesis on the cross-cultural performance of EXMs, against the background of the characteristics of internals/externals as identified by the LOC framework. We will now concisely offer the descriptive statistics of our sample of EXMs.

The sample of 43 EXMs appeared to consist of 15 managers with an external LOC and 28 with an internal LOC (see Figure 1). Clearly, internals have a higher representation in our sample than externals.

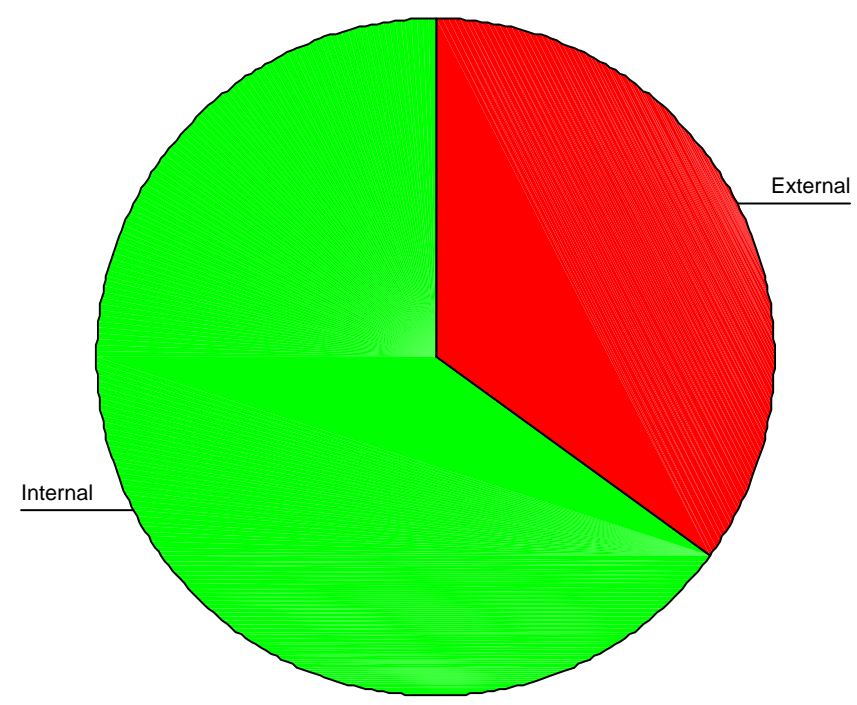

Figure 1. Pie chart of frequencies of the EXM groups (internals and externals). 
Now we will present the frequency distributions of the scores on the CCA scale for our sample of 43 EXMs, irrespective of their classification in the LOC analysis. The graphic illustration of the general scores in the CCA measure is found in Figure 2. This figure shows that the calculated means for all responses of these 43 EXMs is 4.39 (with standard deviation of 1.02)

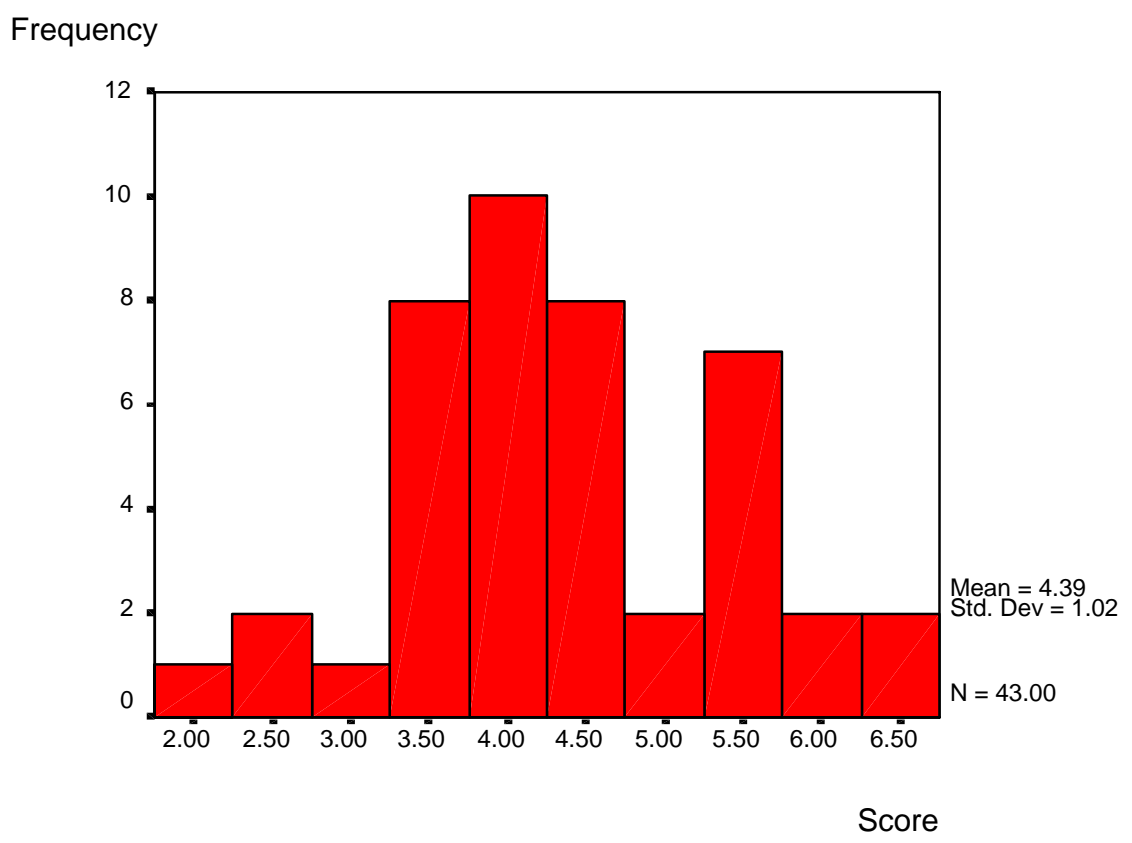

Figure 2. Histogram of the frequencies of the CCA scores

Next, we will take a look at the means of the cross-cultural adjustment scores of the EXMs divided over the 2 LOC categories (internals and externals). Table 1 presents a comparison of the mean scores of both the internal and external groups. It appears that the mean score for the internals (4.85) higher than the mean score for the externals (3.55).

Table 1. Mean cross-cultural adjustment scores of the groups (internals and externals)

\begin{tabular}{|l|l|l|l|}
\hline Group & Mean & N & Standard deviation \\
\hline Internal & 4.8482 & 28 & .8554 \\
External & 3.5460 & 15 & .7397 \\
Total & 4.3940 & 43 & 1.0233 \\
\hline
\end{tabular}


It is also interesting to investigate the distribution of the LOC scores of both internals and externals in the CCA scale. Figure 3 offers a bar chart of the mean scores of the two LOC groups.

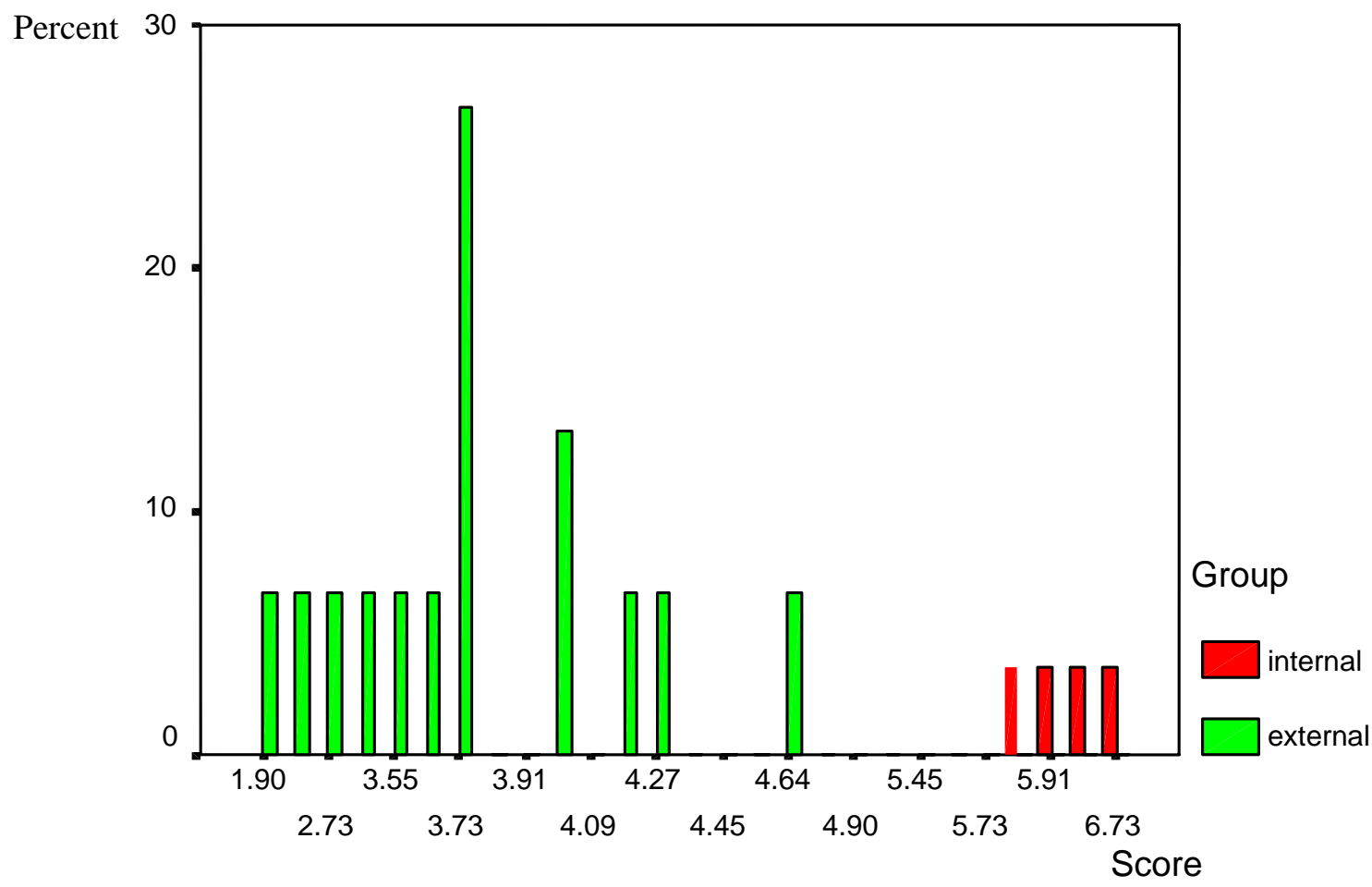

Figure 3. Bar chart of the mean scores of the EXMs' groups.

Finally, we will present the stem-and-leaf plots for both the internal and the external group (see Figure 4). The stem and leaf plots display the scores obtained by the two groups on the CCA scale. It provides both an overview of the score listings as well a general picture of the distributions of the scores by producing a concise, well organized picture of the data.

After these descriptive statistics we will next focus our attention on inferential statistics in order to test our hypothesis on the relationship between LOC scores and CCA performance of EXMs. As mentioned above, we will use two test statistics, viz. an independent sample t-test (assuming a normal distribution of scores) and a MannWhitney non-parametric test (assuming a non-normal distribution of scores). 


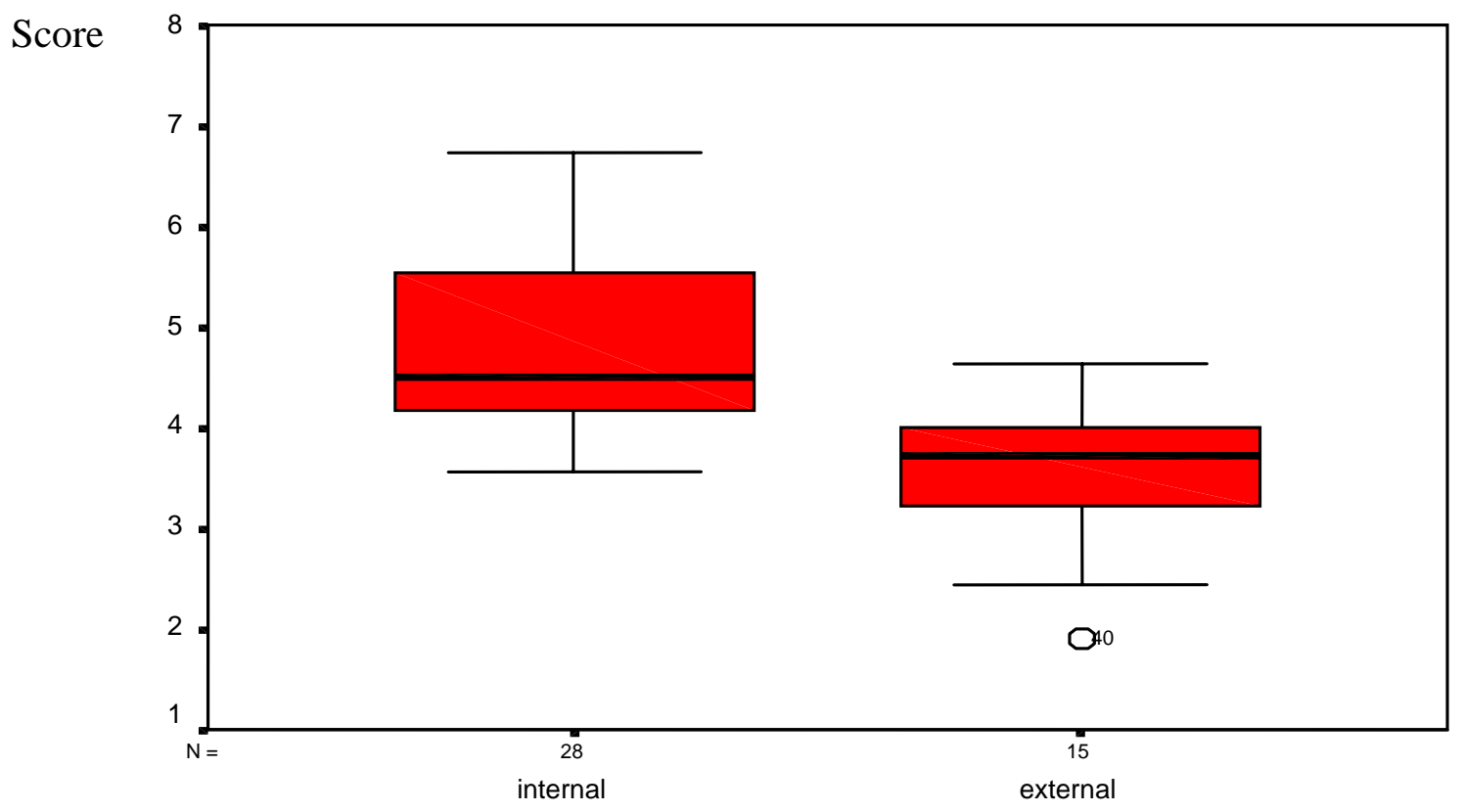

Group

Figure 4. Stem-and-leaf plots for internals and externals

The independent sample t-test procedure compares mean scores for the two groups of cases, based on the assumption that our samples were randomly assigned to the two groups. The t-test produced a value of 4.977, which is larger than the standard threshold value 2, so that this statistic provides support for our hypothesis that internals score significantly higher than externals on the CCA scale.

The Mann-Whitney test is a rather popular one for testing the hypothesis of two independent samples. It is equivalent to the Wilcoxon rank sum test and the KruskalWallis test for two groups. The Mann-Whitney test is used to examine whether two sampled populations are equivalent in location. The p-value of the Mann-Whintney test appeared to be .00 this value supports our main hypothesis that internal EXMs will score higher on the cross-cultural adjustment scale than externals.

We may thus conclude that our main hypothesis is supported. This means that ceteris paribus when offering a temporary assignment to managers in a foreign country, 
internals will tend to have better capabilities of adjusting themselves to the new local culture than externals.

\section{Concluding Remarks}

The present study has examined the possible impact of the LOC of EXMs on their CCA capability. The results of our (limited) experiment in the UK lend support to the hypothesis that managers with an internal LOC perform better than those with an external LOC in terms of adjusting themselves to new socio-cultural conditions in a different host country (see also Hammer et al. 2002).

This study has also confirmed the validity of previous more general behavioural and attitudinal investigations which suggest that personality characteristics affect expatriate success and play a significant role in the adjustment of the individual to a new culture. Most research in the past however, has addressed these issues from the perspective of HRM in relation to expatriate adjustment. Our study has taken its departure from individual data on expatriates themselves, regarding both CCA and LOC. This experiment offers therefore, a necessary complement to previous expatriates' studies. Furthermore, our approach has addressed only these EXMs who did not have a previous expatriate assignment, so as to avoid a biased conclusion from cognitive learning of EXMs with a long-standing international expatriate experience (see e.g., Selmer 2002).

Clearly, our study has some limitations, so that the conclusions have to be interpreted cautiously. Some limitations are:

- $\quad$ the sample is not extensive (43) and concerns only EXMs in the UK.

- $\quad$ the division of the sample over internals and externals - with a dominance of internals - may influence the results.

- $\quad$ the study has addressed only EXMs (i.e., middle and upper class executives), so that the conclusions are not necessarily valid for e.g., technicians and nonmanagerial employees.

- $\quad$ personnel recruitment procedures for jobs of a managerial nature may already lead to a pre-selection of employees with an open eye and creative mind (to be found among people with an internal LOC). 
- $\quad$ our study was based on self-reporting among EXMs, which may cause a tendency towards self-generated validity (Caligiuri 2000).

- $\quad$ our study has focused the attention mainly on LOC constituents, but might need to be extended with other explanatory factors (e.g., language skills, pre-departure training or geographical distance).

- $\quad$ the dichotomic classification of the outcomes of the assignments (i.e., successful or unsuccessful completion) is perhaps rather rigid.

- $\quad$ the sample contained a bias towards EXMs with an Anglo-Saxon background and limits thus the representativeness of our findings for others.

Despite these limitations, the results of our exploratory experiment are interesting and call for more thorough research in which the above limitations are taken care of. Especially in an age of globalisation, it is pertinent to obtain due insight into the motivations, success conditions and failure probabilities of expatriate employees. The failure costs are usually very high and warrant a balanced and profound selection process, in which early-stage scouting, socio-cultural support and training systems, and language skills receive due attention.

In conclusion, our study has clearly generated preliminary but interesting findings. Future research on facilitating and inhibiting factors of CCA may even need panel studies in order to come to grips with the dynamics of adjustment, seen from the perspective of complex cause-effect relationships.

\section{References}

Adams, T.E and N. Kobayashi, The World of Japanese Business, Kodansha International, Tokyo, 1969.

Adler, N.J. and S. Bartholomew, Managing Globally Competent People, Academy of Management Executive, vol. 6, no. 3, 1992, pp. 52-65.

Archer, R., Relationships Between Locus of Control and Anxiety, Journal of Personality Assessment, vol. 43, 1979, pp. 616-617.

Baker, J.C. and J.M. Ivancevich, The Adjustment of American Executives Abroad: Systematic, Haphazard or Chaotic?, California Management Review, vol. 13, no. 3, 1971, pp. 177-182.

Basu, A. and E. Altinay, The Interaction between Culture and Entrepreneurship in

Black, J.S., The relationship of Personal Characteristics with Adjustment of Japanese Expatriate Managers, Management International Review, vol. 30, 1990, pp. 119-134.

Black, J.S., Work Role Transitions: A Study of American Managers In Japan, Journal of International Business Studies, vol. 78, 1998, pp. 277-294.

Black, J.S. and H.B. Gregersen, Antecedents to cross-cultural Adjustment for Expatriates in Pacific Rim Assignments, Human Relations, vol. 44, 1991, pp. 497-515. 
Black, J.S., H.B. Gregersen and M.F. Mendenhall, Global Assignments: Successfully Expatriating and Repatriating International Managers, Jossey-Bass, San Francisco CA, 1992.

Black, J.S., H.B. Gregersen, M.F. Mendenhall and L. Stroh, Globalizing People Through International Assignments, Addison-Wesley Publishing, Reading MA, 1999.

Bono, J.E. and T.A. Judge, Core Self-evaluations, European Journal of Personality, vol. 17, 2003, pp. 518.

Caligiuri, P.M., Selecting Expatriates for Personality Characteristics: A Moderating Effect of Personality on the Relationship between Host National Contact and Cross-cultural Adjustment, Management International Review, vol. 40, 2000, pp. 61-80.

Casson, M., Entrepreneurship and Business Culture, Edward Elgar, Cheltenham, UK, 1995.

Church, A. T., Sojourner Adjustment, Psychological Bulletin, vol. 91, 1982, vol. 3, pp. 540-572.

Copeland, L. and L. Griggs, Going International, Random House, New York, 1985.

Dresser, N., Multicultural manners, John Wiley, New York, 1996.

Furnham, A. and B. Gunter, Corporate Culture: Definition, Diagnosis and Change, International Review of Organziational Psychology (C.L. Cooper and I.T. Robertson, eds.), John Wiley, Chichester, 1993, pp. 233-261.

Gardner, G.H., Cross Cultural Communication, Journal of Social Psychology, vol. 58, 1962, pp. 241-256.

Gertler, M.S., Local Social Knowledge Management, Futures, vol. 36, 2004, pp. 43-51.

Goodstadt, B.E. and L. Hjelle, Power to the Powerless: Locus of Control and the Use of Power, Journal of Personality and Social Psychology, vol. 27, 1973, pp. 190-196.

Gorter, C., P. Nijkamp and J. Poot (eds.), Crossing Borders, Ashgate, Aldershot, UK, 1998

Hammer, M.R., W. Hart and R. Rogan, Can You Come Home Again? An Analysis Of the Repatriation Of Corporate Managers and Spouses, Management International Review, vol. 42, 2002, pp.71-87.

Harris, P., The Unhappy World of the Expatriate, International Management, July, 1979, pp. 49-50.

Hofstede, G., Cultures Consequences: International Differences in Work Related Values, Sage, Beverly Hills CA, 1980.

Hofstede, G., The Cultural Relativity of the Quality of Life Concept, Academy of Management Review, vol. 9, 1984, pp. 389-398.

Hofstede, G., Values Survey Module 1994 Manual, Institute for Research on Intercultural Cooperation, Maastricht, the Netherlands, 1994.

Joe, V.C., Review of the Internal-External Control Construct as a Personality Variable, Psychological Review, vol. 25, 1971, pp. 619-640.

Judge, T.A., E.A. Locke, C.C. Dunham and A.N. Kluger, Dispositional Effects on Life and Job Satisfaction, Journal of Applied Psychology, vol. 83, 1998, pp. 17-34.

Kelman H.C. and L. Bailyn, Effects of Cross Cultural Experiences on National Images: A Study of Scandinavian Students in America, Journal of Conflict Resolution, vol. 6, 1962, pp. 61-75.

Laabs, J., Rating the International Relocation Hotspots, Personnel Journal, vol. 72, 1993, p. 19.

Lanier, A.R., Selecting and Preparing Personnel for Overseas Transfers, Personnel Journal, vol. 58, 1979, pp. 160-163.

Laurent, A., The Cultural Diversity of Western Conceptions of Management, International Studies of Management and Organization, vol. 13, 1983, pp. 75-96.

Levenson, H., Differentiating among Internality, Powerful Others, and Chance, Research with the Locus of Control Construct (H. M. Lefcourt, ed.), vol. 1, Academic Press, New York, 1981, pp. 15-63.

Light, I. and S. Gold, Ethnic Economics, Academic Press, San Diego, 2000.

Littunen, H., Entrepreneurship and the Characteristics of the Entrepreneurial Personality, International Journal of Entrepreneurial Behaviour \& Research, vol. 6, no. 6, 2000, pp. 295-309.

London's Immigrant Businesses, International Small Business Journal, vol. 20, no. 4, 2002, pp. 371-393.

Lysgaard, S., Adjustment in a Foreign Society: Norwegian Fulbright Grantees visiting the US, International Social Science Bulletin, vol. 7, 1995, pp. 45-51.

Marin, R., G. Thomas, K. Charles, O. Epitropaki and R. McNamara, The Role of Leader-Member Exchanges in Mediating the Relationship between Locus of Control and Work Reactions, Journal of Occupational and Organizational Psychology, vol. 78, 2005, pp. 141-147.

Mendenhall, M. and G. Oddou, The Dimensions of Expatriate Acculturation, Academy of Management Review, vol. 10, 1985, pp. 39-47.

Ng, T.W.H., K.L. Sorensen and L.T. Eby, Locus of Control at Work: a Meta-analysis, Journal of Organizational Behaviour, vol. 27, 2006, pp. 1057-1087. 
Nicholson, N., A Theory of Work Role Transitions, Administrative Science Quarterly, vol. 29, 1984, pp. 172-191.

Oberg, K., Culture Shock: Adjustment to a New Cultural Environment, Practical Anthropologist, vol. 7, no. 4, 1960, pp. 177-182.

Ringer, R. C. and R.W. Boss, Hospital Professionals' Use of Upward Influential Tactics, Journal of Managerial Issues, vol. 12, 2000, pp. 92-108.

Ronen, S. and O. Shenkar, Clustering Countries on Attitudinal Dimensions: A Review and Synthesis, Academy of Management Journal, September, 1985, pp. 435-454.

Rotter, J.B., Generalized Expectations for Internal versus External Control of Reinforcement, Psychological Monographs: General and Applied, vol. 80, no. 1, 1966, pp. 1-27.

Rotter, J.B., Some Problems and Misconceptions Related to the Construct of Internal versus External Control of Reinforcement, Journal of Consulting and Clinical Psychology, vol. 43, 1975, pp. 56-67.

Rotter, J.B., Internal versus External Control of Reinforcement, American Psychologist, vol. 45, 1990, pp. 489-493.

Rotter, J., J. Chance and J. Phares (eds.), Applications of a Social Learning Theory of Personality, Holt Rinehart and Winston, New York, 1972.

Selmer, J., Practice Makes Perfect? International Experience and Expatriate Adjustment, Management International Review, vol. 42, 2002, pp. 71-87.

Seward, J., Speaking the Japanese Business Language, European Business, Winter, 1975, pp. 40-47.

Spector, P.E., Behaviour in Organizations as a Function of Employees' Locus of Control, Psychological bulletin, vol. 9, 1982, pp. 482-497.

Spector, P.E., C.L. Cooper and M.E. Aguilar-Vafaie, A Comparative Study of Perceived Job Stressor Sources and Job Strain in American and Iranian Managers, Applied Psychology, vol. 51, 2002, pp. 446-457.

Stening, B.W., Problems of Cross Cultural Contact: A Literature Review, International Journal of Intercultural Relations, vol. 3, 1979, pp. 269-313.

Stroh, L.K. and P.M. Caligiuri, Strategic Human Resources: A New Source for Competitive Advantage in the Global Area, International Journal of Human Resources Management, vol. 9, 1998, pp. 117.

Stroh, L.K., L.E. Dennis and T.C. Craimer, Predictors of Expatriate Adjustment, International Journal of Organizational Analysis, vol. 2, no. 2, 1994, pp. 176-192.

Torbiorn I., Living Abroad, Wiley, New York, 1982.

Triandis, H.C., Dimensions of Cultural Variation as Parameters of Organizational Theories, International studies of Management, vol. 12, 1982, pp. 1-10

Tung, R.L., Selecting and Training for Overseas Assignments, Columbia Journal of World Business, vol. 16, no. 2, 1981, pp. 68-78.

Tung, R.L., The New Expatriates , Ballinger, Cambridge, 1988.

Tung, R.L. and E.L. Miller, Managing in the Twenty First Century: the Need for Global Orientation, Management International Review, vol. 30, 1990, pp. 5-18

Tyson, S. and T. Jackson, The Essence of Organizational Behaviour, Prentice Hall, New York, 1992.

Weissman D., and A. Furnham A., The Expectations and Experience of a Sojourning Temporary Resident Abroad: A Preliminary Study, Human relations, vol. 40, 1987, pp. 313-326.

Windham International and the National Foreign Trade Council, Global Relocation Trends, Survey Report, Windham/NFTC, Washington DC, 1994.

Wong, T.P. and C.F. Sproule, An Attributional Analysis of Locus of Control Construct and the Trent Attribution Profile, Research with the Locus of Control Construct (H. Lefcourt, ed.), vol. 3, Academic Press, New York, 1984, pp. 182-198. 